\title{
O silêncio como prescrição para o trabalho do jornalista
}

\author{
Claudia Nonato \\ Olivia Bulla \\ Roseli Figaro
}

\section{Introdução}

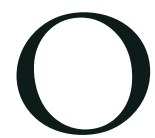

silêncio é uma forma de significado, é uma forma de expressão. O silêncio não é sinônimo de proibição. O silêncio pode significar compreensão, cumplicidade, reflexão, pausa para o mínimo dialógico da fala interior. Poderíamos dizer que há hoje um falatório sem reflexão: nesse sentido, o silêncio faz falta. No entanto, o silêncio de que trata a temática deste artigo é outro. Trata-se do silenciamento, ou seja, do ato impositivo do silêncio. Relaciona-se com o tema da autonomia e da liberdade de expressão no âmbito dos processos de trabalho, no caso, do jornalista, à medida que se estabelecem prescrições para o trabalho que cerceiam o pleno desenvolvimento da atividade do profissional.

É relevante para a nossa discussão esclarecer que o conceito de liberdade de expressão com o qual se opera neste artigo é aquele lastreado pela tradição do republicanismo, ou seja, "a liberdade política do republicanismo, que se define como não-dominação e se orienta pelo modelo das virtudes cívicas da cidadania com valor substancial" (Ramos, 2011: 44), e que se diferencia da compreensão liberal, assentada no "livre agir do indivíduo". Sendo assim, quando se fala em silêncio, censura ou interdição da palavra no mundo do trabalho, afirma-se a operação programada de apagamento de quem trabalha como cidadão, aquele que é ser político.

Nesse sentido, os mecanismos processuais e prescritivos de como trabalhar já contêm as formas de controle da expressão. Geram rotinas produtivas cujo sentido é o de neutralizar as especificidades e as características do fazer, do trabalhar de cada um. Mas as prescrições não dão conta da realidade do trabalho. O trabalho, como 
atividade humana, é mais "complexo" é sempre "inédito", desafiando as "infidelidades do meio" (Schwartz e Durrive, 2007). Essas características do trabalho exigem o ser humano por inteiro, daí os conflitos, as manobras realizadas, os desafios a serem superados e as limitações e os constrangimentos que, no caso da comunicação, são aspectos que levam ao silêncio e à autocensura.

No cotidiano, o silêncio aparece no mundo do trabalho parte como "submissão internalizada" (Freire,1970) e parte como silenciamento da voz do trabalhador. Aquele que trabalha não é visto como criador, realizador, inteligente e ser de comunicação. Para Boutet (2008), o trabalhador não tem direito à palavra no mundo do trabalho. Nos mais diversos ramos profissionais a palavra aparece domada. Como se fosse possível que as prescrições e normas de procedimentos da instituição pudessem cumprir e abarcar todas as situações de trabalho, mesmo as mais inusitadas.

No jornalismo, o silêncio está implícito. Tratar de um tema implica abrir mão de outro. A seleção e hierarquização dos fatos são categorias da prática jornalística, cujo exercício mobiliza valores que orientam as escolhas e a organização do que será notícia. O que não se diz é que os valores que orientam as escolhas e a forma de organização da notícia são determinados por interesses diversos, econômicos e políticos, os quais são naturalizados e incorporados como "rotinas produtivas". Venício Lima (2011) considera que o silêncio é uma forma de censura disfarçada imposta pela grande mídia em relação a determinados temas. Para ele, a grande mídia é a principal mediadora e construtora dos espaços públicos, e, quando omite algo desse espaço, sonega ou exclui a possibilidade desse tema fazer parte do conhecimento e do debate público.

Para discutir essas formas de silenciamento, apresentamos duas pesquisas, realizadas por investigadores do Centro de Pesquisa em Comunicação e Trabalho (CPCT-ECA-USP): Jornalistas, blogueiros, migrantes da comunicação: em busca de novos arranjos econômicos para o trabalho jornalístico com maior autonomia e liberdade de expressão (Lima, 2015); e A evidência dos números no discurso jornalístico através das relações de comunicação e trabalho (Bulla, 2015).

\section{Contra o silêncio: jornalistas blogueiros em busca da liberdade de expressão}

O jornalismo on-line, os blogs e as ferramentas das redes sociais são inovações nas rotinas profissionais. Para fugir das restrições das empresas tradicionais de comunicação, motivados a buscar atualização tecnológica e por vislumbrarem a possibilidade de gerar informação diferenciada daquela publicada na grande mídia, os jornalistas migram para os blogs, principalmente, porque aspiram "conciliar com mais liberdade o exercício da profissão jornalística com a percepção sobre o mundo social, a política e o próprio jornalismo" (Guazina, 2013: 11). 
A instantaneidade protagonizada pelos novos meios de comunicação trazem maiores desafios para os jornalistas. A pesquisa As mudanças no mundo do trabalho do jornalista ${ }^{1}$ mostra que as redes sociais têm sido uma ferramenta de trabalho importante para estes profissionais. Para buscar fontes, informações de pessoas, famosos, celebridades e até desconhecidos, utiliza-se como aliado o Facebook, o Linkedin e o Twitter, ferramentas que tornaram muitas agendas obsoletas. A notícia em tempo real do webjornalismo, do blog, está à frente da notícia que circula nos demais veículos e também em relação ao poder que hoje uma parcela da população tem de contestar, de criticar, ou de "furar" as empresas de comunicação.

O simples fato de qualquer pessoa ter acesso às informações, e às ferramentas para produzi-las, mesmo sem a mediação de um jornalista, significa, para Bernardo Kucinski (2012) que "houve um avanço civilizatório incremental na esfera dos direitos humanos básicos”. Ignácio Ramonet (2013), por sua vez, considera que "a internet nos permite voltar a sonhar com a democratização da informação". A internet é, para Manuel Castells (2004: 225), de fato, uma tecnologia da liberdade. Mas o autor alerta que a internet "pode libertar os poderosos para oprimir os desinformados, pode levar à exclusão dos desvalorizados pelos conquistadores de valor".

Há 10 anos os jornalistas brasileiros passaram a adotar os blogs como veículos de comunicação. Os blogs fascinaram esses profissionais, seja pela sensação de liberdade que o meio promove, na perspectiva de fugir do poder centralizador da empresa de comunicação, seja pela revitalização que trouxe à profissão, ou pela mudança na produção discursiva do jornalismo. No novo meio, o jornalista escreve sobre o que gosta, investe no jornalismo investigativo, assume integralmente o papel de formador de opinião, com a possibilidade de aprofundar a notícia; além disso, ele pode simplesmente compartilhar um texto com outras pessoas; tem a instantaneidade e rapidez da internet a seu favor e ainda conta com ofeedback do leitor/receptor. Para Luís Mauro Sá Martino (2009: 271), “os blogs desestabilizam algumas certezas da prática jornalística e colocam em questão algumas ideias consagradas a respeito do interior da profissão, de um lado, e da amplitude dos efeitos do jornalismo no espaço público, de outro".

Desse modo, as alternativas às formas de trabalho jornalístico se organizam nas inúmeras iniciativas de profissionais que buscam autonomia e independência em relação a empresas jornalísticas imigrando para os seus blogs. A pesquisa Jornalistas, blogueiros, migrantes da comunicação: em busca de novos arranjos econômicos para o trabalho jornalístico com maior autonomia e liberdade de expressão (Lima, 2015) parte do dado do enorme crescimento de blogs produzidos por jornalistas e busca comprovar duas hipóteses: a) os profissionais do jornalismo com vasta experiência na profissão estão migrando para novas mídias, principalmente para blogs independentes; e b) jornalistas experientes migram para os blogs em busca de maior autonomia, liberdade de expressão e realização profissional. 
O estudo, realizado entre 2011 e 2014, observou as rotinas e produção dos jornalistas nos próprios blogs; pesquisou artigos de sites especializados em jornalismo, como Observatório da Imprensa, Portal IMPRENSA e Comunique-se; e também artigos de revistas científicas; pesquisas acadêmicas (teses e dissertações) e analisou entrevistas de material primário e secundário com jornalistas blogueiros. Foram selecionados 15 profissionais com blogs, posteriormente divididos em dois grupos, baseados na relação com os portais e/ou empresas de comunicação: dependentes (A) e independentes ${ }^{2}(\mathrm{~B})$, sendo que este último grupo possui uma subdivisão, entre blogueiros ligados a portais independentes e aqueles sem vínculo com portais. São eles: Josias de Souza, Juca Kfouri, Leonardo Sakamoto, Reinado Azevedo, Ricardo Kotsho e Ricardo Noblat (Dependentes - ligados a portais de grandes grupos de comunicação); Conceição Oliveira, Renato Rovai, Rodrigo Vianna, Luís Nassif, Luiz Carlos Azenha e Paulo Henrique Amorim (Independentes - ligados a portais também independentes); Altamiro Borges, Altino Machado e Miguel do Rosário (Independentes sem ligação com portais). A partir dessa divisão foi feita uma análise geral do perfil dos blogueiros, detalhando seus meios de produção e de subsistência. E, a partir da fala do grupo de jornalistas blogueiros independentes (B), foram detectadas a existência de redes de conexão e também a formação de uma mídia contra-hegemônica, grupo que evidencia um enfrentamento às tentativas de controle e censura, além da busca por arranjos econômicos alternativos para a subsistência.

No blog o jornalista não precisa da estrutura de uma empresa de comunicação; pode escrever de qualquer local e, principalmente com isenção, sem a interferência de interesses comerciais e/ou das empresas de comunicação. Nessa condição, o jornalista se vê como um empreendedor social, "uma alegoria do trabalhador imaginado pelo sistema capitalista, que integra a vocação, no sentido weberiano; a habilidade empreendedora; a capacidade de ser sustentável, no sentido econômico; e uma imagem de felicidade e realização plena" (Casaqui, 2015). Para o autor, essa seria "a intersecção entre a dimensão comunicacional que constitui o espírito do capitalismo contemporâneo e significados atribuídos ao mundo do trabalho, à cultura corporativa" (idem).

Fiéis à ideia de liberdade trazida pela internet e redes sociais, onde, a princípio, era possível partilhar informações a respeito de qualquer assunto ou pessoa sem restrições, os jornalistas blogueiros começaram a produzir reportagens fora da pauta da grande mídia. A repercussão desse trabalho incomoda principalmente as empresas de comunicação, que detinham, até então, o monopólio da fala, além daqueles políticos, rotineiramente denunciados por corrupção. $\mathrm{Na}$ falta de uma legislação específica que regule a internet, a maneira constantemente encontrada por esses grupos para censurar a mídia digital é recorrer ao sistema judiciário. Assim, deu-se início a uma série de processos contra blogueiros, os quais se veem cerceados judicialmente e também economicamente, devido aos altos custos com advogados e indenizações.

$8 \quad$ ALCEU - n.33 - jul./dez. 2016 
Processar blogueiros não é uma prática recente. O primeiro processo conhecido publicamente aconteceu em 2004, quando os blogueiros Cristiano Dias e Edney Souza foram processados por causa de opiniões de outras pessoas que publicaram no blog. A partir daí os processos começam a se multiplicar, por diversos motivos, mas principalmente por danos morais, proteção à honra e difamação e injúria. E, diante da impossibilidade de bancar as ações, os blogueiros encerram suas páginas. É o que se chama de "censura da toga" ou "censura togada". Venício Lima descarta essa denominação, pois compartilha a posição do ex-ministro Eros Grau que, segundo ele, afirmou em julgamento no Supremo Tribunal Federal que "o juiz está limitado pela lei. O censor não. É descabido falar em censura judicial. Não há censura. Há aplicação da lei. A imprensa precisa de uma lei” (Lima, 2013: 88). Censora ou não, o fato é que, pela falta de uma lei específica para a imprensa, e precisamente, para a mídia digital, a Justiça tem se utilizado de brechas para impor a vontade daqueles que querem censurar as informações.

Essa forma de controle acaba gerando, também, a autocensura, ou o silêncio e omissão impostos pelo próprio jornalista. Para Mattos (2012), a autocensura no jornalismo pode ser identificada tanto na omissão quanto na manipulação dos fatos, pois "o comprometimento político e econômico pode levar um veículo, ou profissional, a adotar certas práticas de manipulação da informação para tirar proveitos escusos delas". Fato é que, por meio da manipulação das informações, a mídia promove distorções na realidade, filtrada pelos veículos de comunicação. No ensaio "Significado político da manipulação na grande imprensa”, Perseu Abramo (2013) afirma que a manipulação da informação é uma das principais características do jornalismo no Brasil, praticado hoje pela grande imprensa. Para ele, a realidade artificial criada pela imprensa acaba se transformando em realidade para a população. Essa distorção dos fatos ocorre, segundo ele, de múltiplas e variadas formas, mas "a gravidade do fenômeno decorre do fato de que ela marca a essência do procedimento geral do conjunto da produção cotidiana da Imprensa".

Kucinski (2002: 541-542) identifica na história da imprensa diversos tipos de uso de autocensura jornalística, a começar por países ibéricos, que a utilizavam "na clandestinidade política e da criminalização da dissidência e do não conformismo por parte das elites dirigentes" (p. 539) à incorporação da autocensura ao ethos do jornalista brasileiro. Também mostra que a autocensura foi utilizada como método ideal de controle da informação ("ao suprimir a própria informação de que a informação está sendo suprimida, a autocensura torna-se, para o opressor, a melhor forma de controlar a informação"), e como sistêmica ("muitos episódios de autocensura durante a ditadura militar eram definidos no âmbito de sistemas jornalísticos, de empresas ou de redações, e não por indivíduos”). 
O Claudio Abramo tem toda a razão do mundo. Ele dizia, a única liberdade de imprensa que existe numa redação é a do dono da empresa, o jornalista vai ter que se submeter a isso, ele até pode se submeter, mas procurando manter uma certa ética, dignidade, não produzindo coisas escrotas, tentando ver o contraditório, conferindo fontes, não dando notícias de forma de escandalização, seguindo a ética do jornalista, ou ele pode tentar ser o mais realista do meio (Borges, 2014).

Neste enunciado, Miro Borges, jornalista blogueiro independente, militante e sem vínculos com empresas de comunicação, demonstra sua convicção de que o jornalista que trabalha para uma empresa, nunca terá liberdade de expressão. Para ele, quem aceita trabalhar nessas condições deve, dentro do possível, ao menos ter uma postura ética e profissional. Para isso, os profissionais estão em constante busca por alternativas para praticar um jornalismo comprometido com os ideais da profissão e, ao mesmo tempo, autônomo, desvinculado do poder hegemônico das empresas de comunicação.

O colaborativismo, que permite a produção coletiva de reportagens, e o crowdfunding, ou financiamento coletivo, utilizado para arrecadar dinheiro pela internet, surgem como novas apostas, baseadas num modelo de jornalismo sem fins lucrativos, voltado para a independência e a cidadania. O surgimento de blogs alternativos e agências de notícias coletivas, como "Ponte - Segurança Pública, Justiça e Direitos Humanos", "Agência Pública de Jornalismo Investigativo" e "Jornalistas Livres", que utilizam esses arranjos, mostram que o jornalismo e os jornalistas estão sempre se reinventando.

A pesquisa chega a conclusões contundentes em relação aos jornalistas blogueiros. A primeira delas é que a total independência e liberdade de expressão desejada pelos blogueiros é ilusória. Como sobreviver, dentro da lógica capitalista, sem um meio de subsistência? Além da difícil relação com os anunciantes, há falta de uma legislação específica, que deixa brechas para medidas judiciais e cerceamento econômico contra os jornalistas blogueiros. A segunda, a censura sai das mãos do poder executivo e passa a ser controlada por decisões judiciais. Consequentemente, aqueles que têm mais recursos conseguem sobreviver ao enfrentamento com a Justiça; aos demais, resta procurar apoio, novas soluções, ou simplesmente encerrar o blog e voltar ao silêncio. A terceira, a estabilidade financeira fora das empresas de comunicação e a dificuldade econômica e jurídica desses arranjos econômicos se constitui no desafio de se manterem com seu discurso contra-hegemônico.

\section{O silêncio mascarado em números}

A problematização da pesquisa "A evidência dos números no discurso jornalístico através das relações de comunicação e trabalho" (Bulla, 2015) buscou evidenciar o uso dos

10 ALCEU - n.33 - jul./dez. 2016 
números como uma estratégia persuasiva para a construção de um sentido de verdade no discurso jornalístico, dando-lhe objetividade. Desse modo, o uso argumentativo dos números na notícia é tido como uma estratégia desviante que silencia outros argumentos mais relevantes para a reflexão crítica do cidadão.

Essas questões são desenvolvidas, tendo como orientação teórico-metodológica o binômio comunicação e trabalho, que considera o mundo do trabalho como mediação fundamental da comunicação, relacionando os conceitos de linguagem e problematizando o processo de produção da notícia. A partir daí, é possível a verificação da forma como esse recurso revela as rotinas produtivas como formas de silenciamento de certos fatos.

O contexto desses signos numéricos para compreender seu significado no mundo do trabalho é a naturalização da correspondência pelo jornalista entre palavras e números, entre fatos e dados. A pesquisa comprova que a quantificação da informação através dos números ajuda a construir a versão que se quer do fato com o consentimento da prescrição dos processos produtivos.

A constatação de que as rotinas de trabalho e as práticas produtivas permitem, e até incentivam, ao enunciador, usar o recurso do número na interpretação dos fatos sociais e na veiculação de notícias, levou à possibilidade de se aplicar categorias de análise capazes de reconhecer as falsidades numéricas no jornalismo a fim de evidenciar como os números e certas rotinas podem ser determinantes na construção da notícia e do olhar do jornalista.

Para elucidar os conceitos envolvidos no problema de pesquisa, buscou-se apreender, empiricamente, a evidência dos números no discurso jornalístico, por meio de um corpus, que consistiu em reportagens publicadas no jornal $\mathrm{O}$ Estado de S. Paulo, doravante Estadão, referentes às manifestações sociais contra o aumento da tarifa de transporte público em São Paulo, em junho de 2013 e, um ano depois, quando protestos foram retomados em meio à Copa do Mundo no Brasil.

Essa avaliação foi confrontada com as observações dos relatos dos jornalistas, por meio de cinco entrevistas com os autores que mais se repetem entre as reportagens selecionadas, o que permitiu entender como o produto jornalístico derivado dos números é tratado e como se dão as decisões que marcam o valor do número e sua representatividade em ressaltar e/ou silenciar o fato noticioso.

Buscamos, com isso, compreender as transformações e reconfigurações na relação trabalho/linguagem acionadas pela atividade de cobertura jornalística do jornal Estadão. A partir desse entendimento procurou-se apreender como se dá o processo de criação da notícia e como os números são erigidos pelas rotinas produtivas a argumento preponderante. Esse desenho metodológico resulta em um ponto de encontro entre a subjetividade do relato individual e as propriedades macrossociológicas do objeto analisado. 
Trata-se de uma tentativa de assumir a discussão em sua complexidade ideológica. Compreender as reconfigurações nas relações de comunicação e trabalho é, então, entender a formação das subjetividades e a importância desse binômio para os sujeitos, em suas dimensões de profissional e cidadão. Como resultado, têm-se mudanças nos valores e nas formas de construir a sociedade, com o jogo do micro e do macrossocial construindo as relações de comunicação.

\section{A força da prescrição}

A fagulha dos protestos que tomaram as cidades brasileiras em meados de 2013, das chamadas Jornadas de Junho, foi a mobilização contra o aumento da tarifa no transporte público urbano na capital paulista convocada pelo Movimento Passe Livre (MPL) no dia 6 daquele mês. Aparentemente despretensiosa, a manifestação liderada por 150 jovens ganhou a manchete dos principais jornais de São Paulo no dia seguinte.

A chamada de capa do Estadão em 7 de junho de 2013 é dividida entre uma notícia econômica e a que se refere ao protesto ocorrido na noite anterior. No título e no texto, os números sobre a manifestação que parou a cidade de São Paulo são usados como recursos para quantificar a informação, ao citar a presença "de cerca de mil pessoas contra o aumento da passagem de ônibus e metrô de $\mathrm{R} \$ 3,00$ para $\mathrm{R} \$ 3,20$ " que "parou o trânsito de algumas das principais vias" da cidade "no horário de pico". Tratava-se, portanto, conforme a manchete daquele dia, de um "protesto contra tarifa" de transporte público protagonizado por um número nem tão grande de pessoas, mas que acabara "em depredação e caos em SP".

Na linha fina, o jornal dizia que os "manifestantes fecharam avenidas, invadiram shoppings e deixaram rastros de destruição". Tal cenário criado buscava ainda qualificar os personagens, dizendo que "pelo menos 50 pessoas ficaram feridas e 15 foram detidas". Ao lado, uma foto cuja legenda é: "vandalismo".

Apenas nesse trecho inicial é possível perceber o papel dado ao número na notícia, quantificando o total de manifestantes, sendo que alguns dos envolvidos foram classificados como "vândalos", que bloquearam o trânsito e provocaram confrontos com a polícia. Para o Estadão, o primeiro dia de protesto contra o aumento da tarifa de ônibus levou "caos" e "depredação" à cidade, causando um dos piores índices de congestionamento do ano, o que acabou por ofuscar, na manchete do jornal, os motivos das reivindicações sociais.

Já na versão dos jornalistas, as manifestações de junho de 2013 foram inusitadas e totalmente inesperadas, demandando dos profissionais um tipo de cobertura que, até então, não era foco do jornal onde eles trabalhavam. "Junho foi algo completamente atípico, foi algo completamente diferente" relata em entrevista Bruno Paes Manso, um dos mais experientes. Tal despreparo, porém, não se dava pelo ineditismo no fato em si, a saber os protestos do Movimento Passe Livre (MPL).

12 ALCEU - n.33 - jul./dez. 2016 
Manso lembra que os protestos do MPL já haviam ocorrido em gestões municipais anteriores, como a do ex-prefeito Gilberto Kassab, que também havia sido "perseguido". "Então não era uma novidade pra gente, em tese". "Era um assunto que não costumava inclusive ser coberto pelo jornal", pois viam "os 'malas' do MPL como um protesto a mais dentre as dezenas que acontecem na cidade".

Nesse relato inicial do jornalista, é possível aferir a linha editorial do Estadão ecoada na fala do profissional. Nem o jornal nem seus empregados demonstravam interesse na cobertura das manifestações feitas pelos "malas" do MPL, que já haviam incomodado outros prefeitos com a principal reivindicação do movimento, a tarifa zero. O assunto era algo que, "inclusive", não era um assunto "coberto" pelo jornal, afirma Manso em uma recorrência semântica que "inclui" o sujeito pertencente ao jornal, à empresa, ao mesmo tempo que "exclui" aquele que também se sente assim na sociedade. O profissional nem se dá conta de que o silenciamento da reivindicação dos manifestantes nas gestões anteriores deveria ser (ou ter sido) objeto de interrogações.

Uma vez que a voz vinda das ruas era silenciada, os números na cobertura das manifestações ganham uma importância para dar "dimensão, compor a matéria e contar a história". É o que observa Caio Do Valle que fez a cobertura das manifestações de 2013 "na retaguarda", direto da redação.

Ele lembra que aí, "existia um confronto de dados, né? Porque a polícia, às vezes, divulgava um número de participantes, e o Passe Livre, outro”. Bruno Ribeiro, que cobriu nas ruas as manifestações de 2013 e de 2014 e concedeu a primeira entrevista para esta pesquisa na redação do Estadão, na companhia de Do Valle, emenda citando uma brincadeira entre os jornalistas, de que "a Polícia pega o total e divide por 10 e o MPL pega o total e multiplica por 10".

Apesar desse "confronto de dados", os números eram usados em destaque, como uma estratégia desviante das demandas e reivindicações sociais dos manifestantes. Para Do Valle, isso acontece "porque, infelizmente, o jornalismo de Cidades está acostumado a fazer esse tipo de cobertura. É mais o ato em si, é mais o que o ato em si provoca do que o que se pede com esse ato". Para ele, trata-se de uma característica intrínseca do próprio "jornalismo de Cidades", tal qual é praticado hoje.

Nota-se, na fala, como o jornalista, alinhado às normas do jornal, relega a relevância na cobertura de questões coletivas, silenciado-as. Ao admitir que a empresa jornalística possui certos valores e normas, o trabalhador reconhece que pode estar suscetível a essas pressões, censurando-se previamente. Como resultado, "os textos que saíram no jornal naquela época, eles estão, eles não condiziam... É muito claro, entre estar lá e ver o jornal do dia seguinte", finaliza Ribeiro.

Em uma situação como essa, caberia ao profissional trazer ao cidadão os elementos sobre a situação da sociedade, naquele momento. Mas o que se viu foi o seu enquadramento à empresa midiática a partir de determinado "óculos social", conforme salienta Schaff (1976), ou os modelos e os padrões perceptivos com os quais os indivíduos enxergam o mundo, criando estereótipos. 
Ao fazer assim, o jornalista e a imprensa criam uma "realidade" que parece real, mas que, na verdade, fabrica os signos necessários para que o jornalismo possa reafirmar os valores na sociedade para a qual a atividade serve. Essa concepção relacionada com as rotinas de trabalho permite enxergar a prescrição como algo que não se resume a uma simples transferência de normas no mundo do trabalho, mas como uma construção de discurso social, produzidos e difundidos para o desenvolvimento do cidadão, imerso nessas contradições.

Nelas, o papel do jornalista acaba sendo o de reafirmar a voz da empresa, com a renormalização da atividade reiterando os valores sociais e ideológicos do jornal. " $\mathrm{O}$ problema é o 'Mesquitinha' que cada um leva dentro de si”, brinca Manso, citando uma frase do colega de trabalho Daniel Piza, morto em 2011.

\section{Categorizando os números}

Ao invés de se valer de uma forma disfarçada de censura, que é o silêncio da grande mídia em relação a determinados temas - ou seja, ao invés de omitir - pode-se também "disfarçar" a notícia, construindo o sentido do texto a partir dos números.

Para essa análise, criaram-se três categorias - porta de entrada, olho vivo, de fôlego - que permitem identificar a dupla conotação da informação que chega ao leitor: a do discurso matemático (da exatidão, da objetividade, da verdade, do conhecimento cientifico) e a do discurso jornalístico, concedendo à mensagem a credibilidade e isenção necessárias, ao mesmo tempo, ofuscando os verdadeiros conteúdos (mercadológico, político e ideológico). A partir dessas categorias é possível aferir que somente em um contexto sem a interferência de interesses comerciais e/ ou de outra natureza é que os números podem se transformar em um recurso jornalístico, informando e compondo a notícia, sem perder a sua essência matemática.

A primeira categoria é chamada de "porta de entrada", está relacionada ao uso de ferramentas referentes ao acesso, e considera que possuir uma variedade de informações de uma maneira confiável, é o passo inicial para a checagem da veracidade dos números, e seu consequente uso no texto. De posse dos números corretos, pode-se partir para a segunda categoria, "olho vivo" que está relacionada à observação.

Após a busca em uma vasta rede verossímil de acesso à informação, é preciso extrair e limpar esses números, pois uma adequada extração e limpeza do que for descrito pelos números permite a interpretação e visualização dos fatos, transformados a partir da observação de dados, relatados em texto. Ao se conseguir descrever o que os números representam, é possível investigar os méritos de questões interessantes.

Essa premissa da investigação define a terceira categoria, "de fôlego", a qual engloba as reportagens que buscam traduzir os fatos no calor dos acontecimentos a partir do acesso a fontes e da observação dos fatos, isento de distorções que podem tendenciar o resultado da investigação.

14 ALCEU - n.33 - jul./dez. 2016 
A ampliação desse olhar sobre o mundo permite resgatar a informação de qualidade, acessível e apresentável. Assim, somente em um ambiente em que haja dedicação mais profunda à interpretação, à criação de relações e à tradução das informações guardadas dentro dos números, é que poderá haver um discurso com relação direta com a verificação e a apuração dos fatos, informando para o conhecimento dos diferentes sentidos que o fato pode adquirir à medida que o número seja contextualizado.

\section{Considerações finais}

As duas pesquisas do CPCT mostram a complexidade da discussão sobre o trabalho do jornalista. As rotinas produtivas, na quais se enquadram as prescrições para o trabalho, estão eivadas por procedimentos naturalizados que engendram a autocensura e desempenhos profissionais discutíveis. Nas empresas jornalísticas tradicionais, o fazer da notícia debate-se com prescrições e normas que dissimulam a editorialização, reafirmando o status quo e silenciando vozes e versões dissidentes. Nos blogs de jornalistas que buscam o exercício de um jornalismo alternativo à grande empresa, a pressão econômica e os processos jurídicos fazem o papel da censura e freiam a possibilidade de iniciativas que poderiam ser significativas para a renovação do jornalismo.

As considerações que se tem a fazer sobre os novos arranjos econômicos para a produção jornalística dizem respeito, sobretudo, aos desafios e à viabilidade de sustentação dessas iniciativas. A qualidade jornalística, a credibilidade e a visibilidade são valores buscados pelos chamados blogueiros independentes, mas eles precisam ultrapassar a barreira da censura econômica e jurídica.

Os resultados das duas pesquisas reafirmam a relevância dos estudos da comunicação no mundo do trabalho e da comunicação como trabalho. Essa perspectiva teórico-metodológica amplia nossa compreensão dos processos comunicacionais, trazendo novos desafios à área.

Claudia Nonato

Professora da FIAM-FAAM e pesquisadora do Centro de Pesquisa em Comunicação e Trabalho (CPCT-ECA/USP). claudia.nonato@uol.com.br

Olivia Bulla

Pesquisadora do Centro de Pesquisa em Comunicação e Trabalho (CPCT-ECA/USP) oliviabulla@gmail.com

Roseli Figaro

Professora da Universidade de São Paulo (USP), coordenadora do Centro de Pesquisa em Comunicação e Trabalho (CPCT-ECA/USP) figaro@uol.com.br

ALCEU - n.33 jul./dez. $2016 \quad 15$ 
Recebido em dezembro de 2015.

Aceito em maio de 2016.

\section{Notas}

1. Pesquisa feita pelo Centro de Pesquisa em Comunicação e Trabalho (CPCTECA/USP), entre os anos de 2009 e 2012. Disponível em: http://www2.eca.usp.br/ comunicacaoetrabalho/wp/index.php/pesquisas/2009-2012/ A síntese dos resultados da pesquisa está no livro As mudanças no mundo do trabalho do jornalista. São Paulo: Atlas, 2013.

2. A categoria dependente e independente refere-se a blogs hospedados ou não em portais de empresas de comunicação tradicionais. Desse modo, independente diz respeito apenas aos blogs mantidos pelos seus próprios criadores por meio de diferentes formas de sustentação.

\section{Referências}

ABRAMO, Perseu. Significado político da manipulação na grande imprensa. In: Padrões de manipulação na grande imprensa. São Paulo: Fundação Perseu Abramo, 2003. Disponível em http://novo.fpabramo.org.br/content/significado-politico-da-manipulacao-na-grande-imprensa. Acesso em 05/03/15.

BOUTET, Josiane. La vie verbal au travail. Des manufactures aux centres d'appels. Toulouse: Octares, 2008.

CASAQUI, Vander. Empreendedorismo social em perspectiva global: bem comum, trabalho e engajamento na retórica do capitalismo contemporâneo. Revista Eletrônica Internacional de Economia Política da Informação, da Comunicaşão e da Cultura (EPTIC) v. 17, $\mathrm{n}$. 1 (2015). Disponível em http://www.seer.ufs.br/index.php/eptic/article/view/3383 Acesso em 05/03/15.

CASTELLS, Manuel. Inovação, liberdade e poder na era da informação. In: MORAES, Dênis de (Org.). Sociedade midiatizada. Rio de Janeiro: Mauad, 2004. p. 225 a 231.

FÍGARO, Roseli. A comunicação como processo de interação verbal e produção de sentidos. Intercom - Sociedade Brasileira de Estudos Interdisciplinares da Comunicação XXXVII Congresso Brasileiro de Ciências da Comunicaşão. Foz do Iguaçu, PR. 2 a 5/9/2014.

; NONATO, C. e GROHMANN, R. As mudanças no mundo do trabalho dos jornalistas. São Paulo: Salta, 2013.

e NONATO, C. A autocensura como aspecto da prática no mundo do trabalho dos jornalistas. Trabalho apresentado no GP Comunicação, Mídias e Liberdade de Expressão, XIV Encontro dos Grupos de Pesquisas em Comunicaşão, evento componente do XXXVII Congresso Brasileiro de Ciências da Comunicação, Foz do Iguaçu (PR), 2 a 5 de setembro de 2014.

KUCINSKI, Bernardo. A primeira vítima: a autocensura durante o regime militar. In: CARNEIRO, Maria Luiza Tucci (Org.). Minorias silenciadas: história da censura no Brasil. São Paulo: EDUSP; Imprensa Oficial do Estado, 2002. p. 533-551.

A nova era da comunicação: reflexões sobre a atual revolução tecnológica e seus impactos no jornalismo. Revista Estudos em Jornalismo e Mídia. Vol. 9, n. 1 - janeiro a junho de 2012, p. 4 a 16. Disponível em:

16 ALCEU - n.33 - jul./dez. 2016 
http://www.periodicos.ufsc.br/index.php/jornalismo/article/view/19846924.2012v9n1p4/2223 Acesso em 18/10/2014.

LIMA, Cláudia do Carmo Nonato. Jornalistas, blogueiros, migrantes da comunicação: em busca de novos arranjos econômicos para o trabalho jornalístico com maior autonomia e liberdade de expressão. 2015. 250 f. Tese (Doutorado em Ciências da Comunicação) - Escola de Comunicações e Artes, Universidade de São Paulo, São Paulo, 2015.

LIMA, Venício A. de. Comunicação e cultura: as ideias de Paulo Freire. $2^{\mathrm{a}}$ ed. rev. Brasília: Editora Universidade de Brasília; Fundação Perseu Abramo, 2011.

. O silêncio como forma de censura. Publicado no Observatório da Imprensa em 22/03/2011. Disponível em http://www.observatoriodaimprensa.com.br/news/view/o-silencio-como-forma-de-censura. Acesso em 15/02/2015.

Liberdade de expressão x liberdade de imprensa: direito à comunicação e democracia. 2. ed. revista e ampliada. São Paulo: Publisher Brasil, 2012.

MARTINO, Luís Mauro Sá. Teoria da comunicação: ideias, conceitos e métodos. Petrópolis: Vozes, 2009.

MATTOS, Sérgio. O jornalismo brasileiro continua sob censura. In: COSTA, Cristina (Org.). Seminários sobre censura. Núcleo de pesquisa em comunicação e censura (NPCC/ ECA/USP). São Paulo: Fapesp; Balão Editorial, 2012.

ORLANDI, Eni. Terra à vista - Discurso do confronto: velho e novo mundo. $2^{\mathrm{a}}$ ed. Campinas: Editora Unicamp, 2008.

RAMONET, Ignacio. In: MORAES, Dênis de (Org.). Meios de comunicação: um poder a serviço de interesses privados? In: Mídia, poder e contrapoder. Da concentração monopólica à democratização da informação. São Paulo: Boitempo; Rio de Janeiro: FAPERJ, 2013.

RAMOS, César Augusto. O modelo liberal e republicano de liberdade: uma escolha disjuntiva? Revista Trans/Form/Ação, Marília, v.34, n.1, p. 43-66, 2011.

SCHWARTZ, Yves e DURRIVE, Louis. (Orgs.) Trabalho E Ergologia: conversas sobre a atividade humana. Niterói: Eduff, 2007.

VAINER, Carlos. Quando a cidade vai às ruas. In: MARICATO, Ermínia et al. Cidades rebeldes - Passe Livre e as manifestações que tomaram as ruas do Brasil. São Paulo: Boitempo: Carta Maior, 2013. 


\section{Resumo}

O artigo apresenta uma discussão sobre o silenciamento, ou o ato impositivo do silêncio, como prescrição para o trabalho do jornalista. Para tanto, desenvolvemos o tema em dois tipos de problematização: a) os jornalistas que migram para os blogs, o fazem em busca de maior autonomia, para fugir das prescrições coercitivas das empresas de mídias tradicionais; b) a prescrição para o uso argumentativo dos números configura-se como estratégia persuasiva desviante, que, por sua aparente força de objetividade, silencia outros argumentos mais relevantes para a reflexão crítica do cidadão, consumidor do jornalismo. Essas duas questões são abordadas, tendo como orientação conceitual o binômio comunicação e trabalho e os resultados das pesquisas do Centro de Pesquisas em Comunicação e Trabalho - CPCT, da ECA-USP, membro da Rede de Estudos sobre Trabalho e Identidade do Jornalista.

\section{Palavras-chave}

Silêncio. Jornalista. Comunicação e trabalho. Prescrição. Censura.

\section{Abstract}

Silence as a prescription for the work of journalist

The paper presents a discussion of silencing, or the act of imposing silence, like prescription for the work of the journalist. We develop the theme in two types of questioning: a) journalists who flock to blogs, are seeking greater autonomy, to escape the coercive prescriptions of traditional media companies; b) prescribing for argumentative use of numbers appears as deviant persuasive strategy, which, in apparent strength of objectivity, silent other most important arguments for critical reflection of citizen journalism consumer. These two issues are addressed, with the conceptual orientation the binomial communication and work and the results of the research from Center of Research in Communication and Works - CPCT the ECA-USP, a member of the Research Network on Labour and Journalist Identity.

\section{Keywords}

Silence. Journalist. Communication and work. Prescription. Censorship. 